\title{
Blockchain Technology in India - Challenges and Opportunities
}

\author{
K. Shruthi, Tamilarasi. M
}

\begin{abstract}
The Blockchain is a distributed database of all transactions or digital events that is maintained as Blocks. These transaction records that are executed between parties are stored as blocks in Blockchain and shared among parties that maintain the blocks. Each Block is analyzed, verified and stored by the parties who are part of the network/system. Each block contains the details of a single transaction and a hash key of the previous block.

Digital Crypto Currency and Bitcoin use Blockchain as its backbone. By design, Blockchains are much secured and the technology ensures flawless record keeping. The Crypto Currency, Bitcoin which is used as a decentralized digital currency shall be transacted peer-to-peer without any third party involvement. Other areas like financial transactions, identity management, food traceability, medical records, even election processes shall be secured using Blockchain.

Electronic payments have made a major breakthrough in Indian banking sector and continue to grow with more innovations in the enhancements to the existing system. Slowly Electronic payments are replacing paper based transactions which saves time and cost. Volume of transactions has also increased with more transparency and the sector is showcasing good progress.

Introduction of Bitcoin and crypto currencies in Finance and Banking sectors have brought in a paradigm shift on the fundamental transaction processes of this sector. Essential elements of trade, ownership and trust are ensured through Blockchain which makes a disruptive intervention on whole transaction management model. Constructive and critical exploration of this technology in the context of India will bring out more prospective on how this technology shall be leveraged. This paper will present the current state of Blockchain adoption in India and will cover the challenges and opportunities in this space..
\end{abstract}

Keywords : Blockchain, Bitcoin, Cryptocurrency, Digital Transaction, Encryption.

\section{INTRODUCTION}

$\mathrm{B}_{\text {lockchain technology distributes the details of every }}$ transaction as a block to all the computers in the network. The computers in the network validate the block and add it to the chain. This chain acts as the foot print for the history of the transaction which cannot be tampered. These transactions cannot be modified without the knowledge of all

the parties/computers that maintain the chain.

Blockchain in banking application will provide a powerful

Revised Manuscript Received on December 05, 2019.

* Correspondence Author

K. Shruthi*, M.Phil Research Scholar, Department of Commerce, Madras Christian College, Chennai, India. Email: janyashruthi@gmail.com

Dr. Mrs. Tamilarasi. M, Professor \& HOD of Commerce, Madras Christian College, Chennai, India. tool for bank transaction in making transaction faster and transparent. Even though the technology seems to be complex with cryptography, distributed databases, network of systems etc. the user interface implementation will be made simple for ease of use by banking staff and end users.

In addition to enabling trade in the banking sector, Blockchain makes nearly impossible for a hacker to modify the store transaction data, it also eliminates any errors and duplication that could creep due to process gaps.

Even though there exists many crypto currencies like, Litecoin, Ethereum, Zcash, Dash, etc., Bitcoin is the most popular among others and it is one of the best use case for the use of Blockchain technology.

\section{LITERATURE REVIEW}

Satoshi Nakamoto (2008) introduced the application of Bitcoin though a technology platform that enabled a peer-to-peer electronic transfer of cash which between two parties without routing it through a financial intermediary. This triggered the approach of using Blockchain for secured transactions.

Melanie Swan (2015) explains that a decentralized database which shall hold public ledger of transactions involving tangible entities like, financial transfers, inventory logistics, registration details of properties; and intangible entities like health care, election process, can be implemented in Blockchain platform.

Harsha Gandhi, et al (2019) states that the hash function used in Blockchain is tamper-proof through public key encryption and offers enhanced security solution with improved portability and reduced time.

\section{PROBLEM STATEMENT}

Till early 90s people used to do all banking transactions in-person at the Bank. After the widespread of Internet in late 90s, Banks started introducing eTransfers and it eased the process of transfers and also reduced the time considerably. Subsequently, credit cards where introduced, which enabled the customer to do cashless transactions. Smart phones and Mobile apps advanced the payment/money-transfer processes and made it very simple and efficient for end users. Later on, by mid of 2010 s many payment gateways \& apps surfaced, this made customers to pay bills and make on-line purchase in no time, at their convenience and from anywhere. Even though the technology was growing on one side, the inherent risk associated with eTransfer has also increased exponential which is challenging the growth and

benefit of eTransfers and

Published By:

Blue Eyes Intelligence Engineering 
payments. There is a need for a fool proof mechanism to ensure that all these electronic modes of transactions are safe and secure.

\section{OBJECTIVE OF THE STUDY}

The main objective is to study current adoption of Blockchain in India and understand its challenges and opportunities. The study also brings out the acceptance to Blockchain across a population through a survey.

\section{RESEARCH METHODOLOGY}

Responses of the survey questionnaire are the primary sources of study. A simple random sample size of 50 respondents from Chennai was involved in the survey. This sample technique is time tested and fool-proof method for collecting response data from diversified population. This method is less time consuming and economically, however the effectiveness of the survey depends on the population selected. Data thus collected, was processed using chi square test , the results were analyzed and interpreted appropriately.

\section{BLOCKCHAIN IN INDIA}

ICICI Bank and Emirates NBD announced launch of Blockchain network for international remittances and trade finance as a pilot. Mahindra group and global IT solution provider IBM announced intention to build a cloud-based Blockchain-backed supply chain finance application which has a potential to reinvent the supplier-to-manufacturer finance transaction system in the country. Bajaj Electricals announced using Blockchain in smart contracting in area of vendor / supplier financing. With support from Yes Bank, IBM and a fintech start-up, Cateina Technologies. The Land Records Department and the Transport Department of the Government of Andhra Pradesh have recently implemented a Blockchain pilot. Telecom Regulatory Authority of India (TRAI) is in the process of implementing Blockchain to keep irritating spam telephone calls and messages under control, perhaps the first of its kind usage in the telecom sector. The Aadhar project of UIDAI is undoubtedly a massive implementation of demographic and biometric technology ever done by any government agency so far.

\section{A. Challenges}

As the process for profit or commission is not defined in India, it stands as a challenge in creating an independent Blockchain solution. ICOs and crypto currencies are important for fund raising of Blockchain startups, however, we are yet to make in breakthrough in both. There is a huge need for Blockchain skilled work force in India; leading institutes have just started to offer Blockchain courses. Other areas of challenges in Blockchain are Interoperability, Energy Consumption, Legal Framework, etc. One another hindrance is with respect to the regulations it faces on an authoritative level. Apart from this, it is expected to grow rapidly.

\section{B. Opportunities}

For the sectors impacting the digital economy, The Government of India is strongly recommending the use of Blockchain. With more and more citizens using electronic transactions, Blockchain shall be offered to all citizens at an economic rate. With factors such Growing Infrastructure, Cross-Sector Acceptance, Data Security and Data Privacy emphasizes the need for Blockchain, there are various sectors which includes, but not limited to, Digital Identity, Digital Records, Secured Voting, Health Care, Digital Payments, Insurance and Smart Contracts are potential application areas of Blockchain.

NITI Aayog's pilot project, IndiaChain will provide vast employment opportunities in Blockchain space. There is plenty scope for more jobs to be created in this sector in the future, as By the year 2002, the global market for services and products related to Blockchain are expected to reach $\$ 7.7$ billion, which expands the job opportunities across the board.

\section{RESULTS AND DISCUSSION}

\section{A. Demographic Profile of the population under survey}

Figure - 1: Demographic Profile

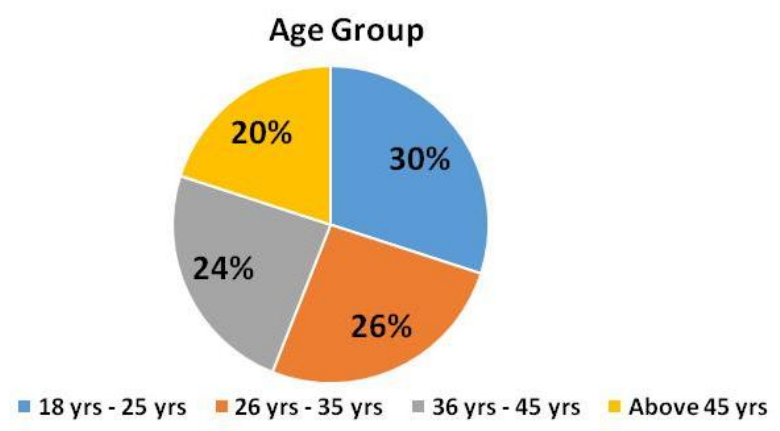

Education

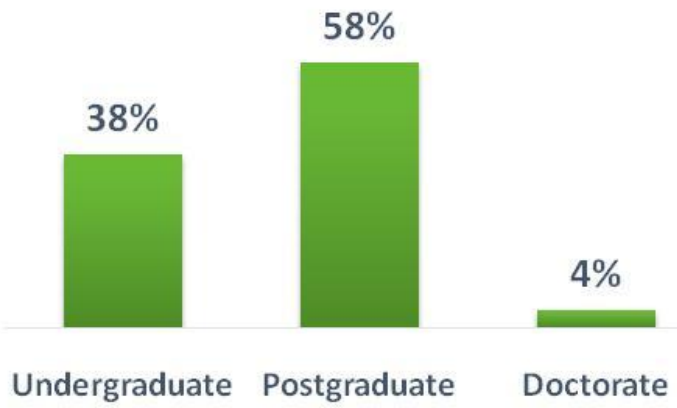

Undergraduate Postgraduate Doctorate 


\section{Profession}

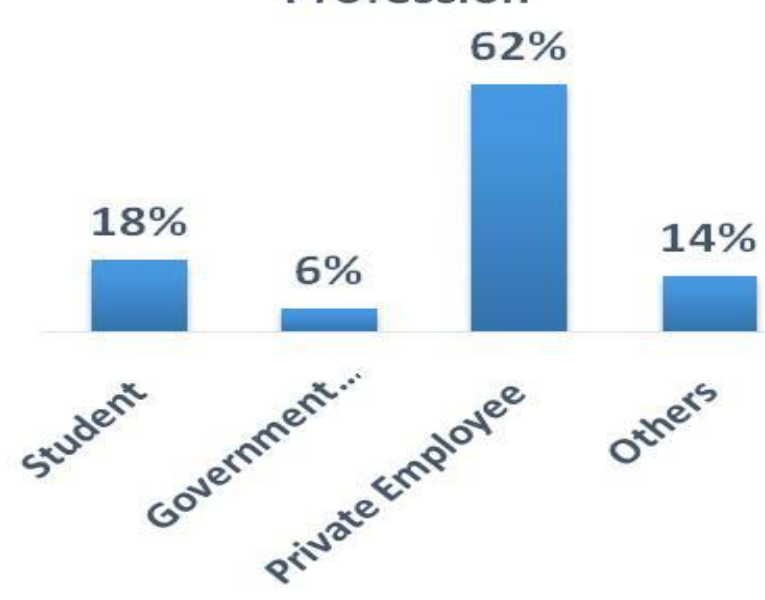

Interpretation: Graphs1 shows that out of total 50 respondents, $56 \%$ are of the age group $18-35$ years and $44 \%$ are of age group of $>35$ years. There were $58 \%$ Postgraduate respondents taken for the study and $38 \%$ of the study was done with Undergraduate respondents. Out of all respondents, $62 \%$ of the respondents were Private Employees.

\section{HYPOTHESIS OF STUDY}

$\mathbf{H}_{\mathbf{1}}$ : There is no significant difference between age and digital identity

$\mathbf{H}_{2}$ : There is no significant difference between age and digital records

$\mathbf{H}_{3}$ : There is no significant difference between age and secured voting

$\mathbf{H}_{4}$ : There is no significant difference between age and health care

$\mathbf{H}_{5}$ : There is no significant difference between age and digital payments

$\mathbf{H}_{6}$ : There is no significant difference between age and insurance

$\mathbf{H}_{7}$ : There is no significant difference between age and smart contracts

\section{A. Data Analysis And Interpretation (Chi-Square)}

Table - 1: Age and Digital Identity - Chi-Square Tests

\begin{tabular}{|l|c|c|c|}
\hline & Value & Df & $\begin{array}{c}\text { Asymp. Sig. } \\
\text { (2-sided) }\end{array}$ \\
\hline Pearson Chi-Square & $16.182 \mathrm{a}$ & 12 & .183 \\
\hline Likelihood Ratio & 15.109 & 12 & .236 \\
\hline Fisher's Exact Test & 12.275 & & \\
\hline Linear-by-Linear Association & $.386 \mathrm{c}$ & 1 & .534 \\
\hline N of Valid Cases & 50 & & \\
\hline
\end{tabular}

Interpretation: The chi square table shows that relationship between age and digital identity is 0.183 .This indicates weak positive relationship between the variables. Thus null hypothesis $\mathrm{H}_{1}$ (There is no significant difference between Age and Digital identity) is rejected.
Table - 2: Age and Digital Records - Chi-Square Tests

\begin{tabular}{|l|c|c|c|}
\hline & Value & Df & $\begin{array}{c}\text { Asymp. Sig. } \\
\text { (2-sided) }\end{array}$ \\
\hline Pearson Chi-Square & $12.255 \mathrm{a}$ & 9 & .199 \\
\hline Likelihood Ratio & 13.593 & 9 & .138 \\
\hline Fisher's Exact Test & 9.845 & & \\
\hline Linear-by-Linear Association & $.050 \mathrm{c}$ & 1 & .824 \\
\hline N of Valid Cases & 50 & & \\
\hline
\end{tabular}

Interpretation: The chi square table shows that relationship between age and digital records is 0.199. This indicates weak positive relationship between the variables. Thus null hypothesis H2 (There is no significant difference between Age and Digital records) is rejected.

Table - 3: Age and Secured Voting - Chi-Square Tests

\begin{tabular}{|l|c|c|c|}
\hline & Value & Df & $\begin{array}{c}\text { Asymp. Sig. } \\
\text { (2-sided) }\end{array}$ \\
\hline Pearson Chi-Square & $14.518 \mathrm{a}$ & 9 & .105 \\
\hline Likelihood Ratio & 15.368 & 9 & .081 \\
\hline Fisher's Exact Test & 12.140 & & \\
\hline Linear-by-Linear Association & $2.925 \mathrm{c}$ & 1 & .087 \\
\hline N of Valid Cases & 50 & & \\
\hline
\end{tabular}

Interpretation: The chi square table shows that relationship between age and secured voting is 0.105 .This indicates weak positive relationship between the variables. Thus null hypothesis $\mathrm{H} 3$ (There is no significant relationship between age and secured voting) is rejected.

Table - 4: Age and Health Care - Chi-Square Tests

\begin{tabular}{|l|c|c|c|}
\hline & Value & Df & Asymp. Sig. (2-sided) \\
\hline Pearson Chi-Square & $4.903 \mathrm{a}$ & 9 & .443 \\
\hline Likelihood Ratio & 5.148 & 9 & .821 \\
\hline Fisher's Exact Test & 5.782 & & .248 \\
\hline Linear-by-Linear Association & $1.334 \mathrm{c}$ & 1 & \\
\hline of Valid Cases & 50 & & \\
\hline
\end{tabular}

Interpretation: The chi square table shows that relationship between age and digital identity is 0.443 . This indicates weak positive relationship between the variables. Thus null hypothesis H4 (There is a no significant relationship between age and healthcare)is rejected. 
Table - 5: Age and Digital Payments - Chi-Square Tests

\begin{tabular}{|l|c|c|c|}
\hline & Value & Df & $\begin{array}{c}\text { Asymp. Sig. } \\
\text { (2-sided) }\end{array}$ \\
\hline Pearson Chi-Square & $12.544 \mathrm{a}$ & 12 & .403 \\
\hline Likelihood Ratio & 16.240 & 12 & .180 \\
\hline Fisher's Exact Test & 12.854 & & \\
\hline Linear-by-Linear Association & $.702 \mathrm{c}$ & 1 & .402 \\
\hline N of Valid Cases & 50 & & \\
\hline
\end{tabular}

Interpretation: The chi square table shows that relationship between age and digital payments is 0.403.This indicates weak positive relationship between the variables. Thus null hypothesis H5 (There is no significant relationship between age and digital payments)is rejected.

Table - 6: Age and Insurance - Chi-Square Tests

\begin{tabular}{|c|c|c|c|}
\hline & Value & Df & $\begin{array}{c}\text { Asymp. Sig. } \\
\text { (2-sided) }\end{array}$ \\
\hline Pearson Chi-Square & $11.522 \mathrm{a}$ & 12 & .485 \\
\hline Likelihood Ratio & 12.498 & 12 & .407 \\
\hline Fisher's Exact Test & 9.977 & & \\
\hline Linear-by-Linear Association & $4.237 \mathrm{c}$ & 1 & .040 \\
\hline N of Valid Cases & 50 & & \\
\hline
\end{tabular}

Interpretation: The chi square table shows that relationship between age and digital identity is 0.183 . This indicates weak positive relationship between the variables. Thus null hypothesis H6 (There is no significant relationship between age and insurance)is rejected.

Table - 7: Age and Smart Contracts - Chi-Square Tests

\begin{tabular}{|c|c|c|c|}
\hline & Value & Df & $\begin{array}{c}\text { Asymp. Sig. } \\
\text { (2-sided) }\end{array}$ \\
\hline Pearson Chi-Square & $11.149 \mathrm{a}$ & 12 & .486 \\
\hline Likelihood Ratio & 11.921 & 12 & .452 \\
\hline Fisher's Exact Test & 9.647 & & \\
\hline Linear-by-Linear Association & $.046 \mathrm{c}$ & 1 & .831 \\
\hline N of Valid Cases & 50 & & \\
\hline
\end{tabular}

Interpretation: The chi square table shows that relationship between age and smart contracts is 0.486 . This indicates weak positive relationship between the variables. Thus null hypothesis $\mathrm{H} 7$ (There is no significant relationship between age and smart contracts) is rejected.

\section{FINDINGS FROM THE STUDY}

Three major factors where identified in the survey analysis

- The first factor, Comfort \& Security, how safe are the transfer/bill-pays are safe over internet, $44 \%$ think that the current systems that we have are secure, however $56 \%$ even though they use internet for transactions, still they believe that it is insecure and it has to be improved. In spite of security aspect, $80 \%$ has felt online transaction are comfortable.
- IThe second factor, Awareness, only 34\% and 40\% are aware on Blockchain \& Bitcoin respectively, which means more awareness is required on security of transactions and followed by technology/process that enables security.

- The third factor, Acceptance, where $26 \%$ of responds agree that Blockchain is needed for Digital Payments, Secured Voting \& Health Care, 5\% strongly agree that Blockchain make sense of Smart Contracts.

\section{CONCLUSION}

The opportunities for Blockchain in India is abundant and there is a need for distributive approach in many areas to save money and time while ensuring secure \& safe transactions. Even though $54 \%$ agree to the need of Blockchain in transaction management, the awareness is less. As more and more Governments, Regulators and Agencies transform their service offering to Blockchain, it will make India to be more productive in saving time and efforts. The adaption of Blockchain in India has started across various sectors, however it might take some time to get the acceptance of public and implement it across different interventions of day to day transactions.

\section{SCOPE FOR FURTHER RESEARCH}

This study has identified acceptance scope for Blockchain in a set of applicable areas. The future researchers can identify the opportunities to increase awareness and usage of Blockchain. The study has focused only on specific geography, further research shall focus on the other geographic areas, to understand behavior patterns of heterogeneous groups.

\section{REFERENCES}

1. Rishav Chatterjee, Rajdeep Chatterjee, "An overview of the emerging technology: Blockchain", 2017 3rd International Conference on Computational Intelligence and Networks (CINE), October 2017.

2. Sachchidanand Singh, Nirmala Singh, "Blockchain: Future of financial and cyber security", 2016 2nd International Conference on Contemporary Computing and Informatics (IC3I), December 2016.

3. Ehsani, Farzam, "Blockchain in Finance: From Buzzword to Watchword", CoinDesk (News), December 2016.

4. SebastianSchuetz, ViswanathVenkatesh, "Blockchain, adoption, and financial inclusion in India: Research opportunities", International Journal of Information Management, May 2019.

5. Bhargava, Richa, "Blockchain Technology and Its Application: A Review", IUP Journal of Information Technology; Hyderabad Vol. 15, Iss. 1, March 2019.

6. Harsha Gandhi, Rupali More, Nainisha Patil, "A Blockchain in Banking Application”, Global Journal for Research Analysis, April 2019.

7. Subodh Kesharwani, Madhulika P. Sarkar, Shailza, Jyoti, "Blockchain and Digital Payments-The New Paradigm", Cybernomics- An International Periodical, May 2019. 


\section{AUTHORS PROFILE}

Ms. Shruthi.K has completed post graduation in commerce. She has presented research papers in international conferences.

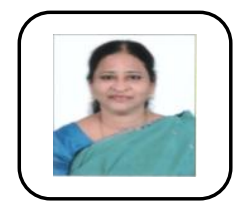

Dr. Tamilarasi Mailachalam joined the department as a faculty in the year 1988. Her doctoral research was on "PERCEPTION OF NRI'S(USA)OF E-BANKING

SERVICES IN INDIA". She has presented many research papers in national and international conferences organized by various universities across the county and her papers awarded as best paper in many conferences. Her research and teaching interests include taxation, economics, law, business maths \& statistics, training and development, business communication. She has published more than 100 of her research papers in various reputed referred national, international journals and books and organized many international conference. 